\title{
Geschäftsbericht 2012
}

Im Geschäftsjahr 2012 (Dezember 2011 bis Dezember 2012) wurden bei der Redaktion der Sozialen Welt 35 Manuskripte und vier Debattenbeiträge eingereicht. Nach Überarbeitung angenommen wurden 16 Manuskripte und vier Debattenbeiträge. Abgelehnt wurden demnach 19 Manuskripte. Dies entspricht einer Gesamtablehnungsquote von 54 \%. Die Entscheidungen der Herausgeber wurden durch 49 auswärtige Fachgutachten unterstützt. 